\title{
ERRATUM
}

\section{Metacognition, borderline pathology and psychotherapeutic change: a single-case study}

Raffaella Perrella, ${ }^{1}$ Antonio Semerari, ${ }^{2}$ Francesca Scafuto, ${ }^{3}$ Giorgio Caviglia ${ }^{1}$

${ }^{1}$ Department of Psychology, Second University of Naples; ${ }^{2}$ Third Center of Cognitive Psychotherapy, Rome; ${ }^{3}$ Department of Political Sciences, Federico II University, Naples, Italy

Due to an error, Dr. Francesca Scafuto was omitted from the author list of this article (published in 2013 in Research in Psychotherapy: Psychopathology, Process and Outcome 16(2):102-108. DOI: 10.4081/ripppo.2013.126). The correct author details appear above.

Research in Psychotherapy: Psychopathology, Process and Outcome, 21(1):62. DOI: $10.4081 /$ ripppo.2018.298 